\title{
Percursos para promoção da saúde bucal: a capacitação de líderes na Pastoral da Criança da Igreja Católica no Brasil*
}

\author{
Silvia Maria Prado Lopes Queiroz ${ }^{1}$ \\ Samuel Jorge Moysés ${ }^{2}$ \\ Beatriz Helena Sotille França ${ }^{3}$ \\ Julio César Bisinelli ${ }^{4}$ \\ Simone Tetu Moysés 5
}

QUEIROZ, S.M.P.L. et al. Paths for promoting oral health: capacitation among leaders of the Children's Pastoral Mission of the Catholic Church in Brazil. Interface - Comunic., Saude, Educ., v.14, n.34, p.619-32, jul./set. 2010.

The purpose of this evaluative study was to analyze capacitation among of the Children's Pastoral Mission of the Catholic Church, and to identify potentials and weaknesses with regard to oral health promotion. Rapid evaluation methodology of participatory nature was used. Evaluation workshops were held, documents were analyzed, key informants were interviewed, focus groups were held and participants were observed during leader guidance training. With empowerment and comprehensiveness as the interpretative categories, content analysis was performed. Oral health was dealt with such that it was integrated with other topics, and complementary actions supported the educational activities. The pedagogical trend adopted by the institution involved the principle of empowerment. However, technical questions were given greater emphasis than were pedagogical questions.

Discussions on pedagogical issues and working in networks, for capacitation, were considered fundamental points for consolidating and amplifying the action evaluated.

Keywords: Health promotion. Health education. Empowerment. Comprehensiveness. Social networks.
O propósito desta pesquisa avaliativa foi analisar a capacitação dos líderes da Pastoral da Criança da Igreja Católica e identificar potencialidades e fragilidades para promoção da saúde bucal. Utilizouse a Metodologia de Avaliação Rápida, de caráter participativo. Foram realizadas oficinas de avaliação, análises documentais, entrevistas com informantes-chave, grupos focais e observação participante de uma capacitação no Guia do Líder. Tendo como categorias interpretativas o empoderamento e a integralidade, procedeu-se à análise de conteúdo. A saúde bucal é trabalhada de forma integrada aos demais temas e ações complementares dão suporte às ações educativas. A tendência pedagógica adotada pela instituição pesquisada contempla o princípio do empoderamento. Contudo, questões técnicas tiveram maior ênfase na capacitação do que as pedagógicas. Discussões sobre questões pedagógicas e trabalho em redes, nas capacitações, foram consideradas pontos fundamentais para consolidação e ampliação da ação avaliada.

Palavras-chave: Promoção da saúde. Educação em saúde. Empoderamento. Integralidade. Redes sociais.

\footnotetext{
* Elaborado com base em Queiroz (2008). O projeto de pesquisa foi registrado no Comitê de Ética da Pontifícia Universidade Católica do Paraná e financiado pelo CNPq. ${ }^{1}$ Instituto Federal do Paraná. Rua Augusto Severo, 1001, apto. 502, 80.030-240. silvia.queiroz@ifpr.edu.br 2-5 Pontifícia Universidade Católica do Paraná
} 


\section{Introdução}

As sucessivas Cartas da Promoção da Saúde (Brasil, 2002) têm, como um de seus núcleos filosóficos, o conceito de potencialização ou empowerment. Este conceito, usualmente traduzido no Brasil como empoderamento, resgata a dimensão da educação em saúde, porém, mais do que repassar informações e induzir a determinados comportamentos, visa um aumento do poder político por parte de indivíduos e comunidades, capacitando-os para atuarem como atores diretos de sua própria transformação social (Carvalho, 2004; Buss, 2000).

Contudo, alguns autores afirmam que o termo empoderamento pode ser utilizado com diversos sentidos, servindo a diferentes objetivos. Pode estar ligado a processos de mobilização e práticas para promover a autonomia, a consciência crítica e a melhora das condições de vida de grupos e comunidades. Por outro lado, pode referir-se a ações que se destinam a promover a integração dos excluídos em sistemas precários e ações sociais assistencialistas, que não contribuem para organizálos (Gohn, 2004). O termo pode ser utilizado, ainda que no sentido de autonomia, para sugerir que as pessoas utilizem cada vez mais recursos próprios e/ou das comunidades, justificando a diminuição de recursos estatais na prestação de serviços sociais e de saúde, em tempos de ajustes neoliberais (Carvalho, 2004). Neste trabalho, o empoderamento foi tomado como categoria interpretativa, enquanto um processo de capacitação (aquisição de conhecimentos) e de poder político, que procura possibilitar que indivíduos e coletivos aumentem o controle sobre os determinantes da saúde, para melhorá-la (Buss, 2000; World Health Organization - WHO, 1986).

Ao buscar as formas de operacionalizar esse conceito, a própria Carta de Ottawa destaca a necessidade de total e constante acesso à informação e à educação sanitária para o reforço da ação comunitária, bem como para o desenvolvimento de aptidões pessoais (WHO, 1986). Contudo, dependendo da tendência pedagógica adotada, um processo educativo pode aproximar-se ou afastar-se do conceito de empoderamento. Wallerstein (WHO, 2006) afirma que o processo de empoderamento tem sido beneficiado, em todo o mundo, pela filosofia da educação libertadora de Paulo Freire. A pedagogia libertadora ou da problematização possibilita uma prática educativa mais participativa e dialógica, onde a realidade das relações do homem com a natureza e com os outros homens é questionada visando sua transformação (Pereira, 2003). Já a educação tradicional, denominada por Freire de "bancária", onde o educando recebe passivamente os conhecimentos, não se mostra adequada para tal fim, já que, dentre suas repercussões em nível individual e coletivo, estão: a falta de atitude crítica e problematização da realidade, o individualismo e falta de participação, submissão à dominação e a manutenção do status quo (Bordenave, 1989).

A maioria das propostas educativas em saúde tem sido calcada na transmissão de conhecimento especializado para uma população cujo saber é desvalorizado ou ignorado, distanciando-as do conceito de empoderamento (Meyer, Mello, Ayres, 2006). Outra questão importante é que elas acontecem majoritariamente de forma isolada e desconectada de ações que lhes deem suporte, ferindo outro princípio da promoção da saúde: a integralidade. Esse princípio orienta que as iniciativas fomentem a saúde física, mental, social e espiritual, em sua ampla determinação, o que só pode ser alcançado por meio de ações que ultrapassem o setor saúde (Westphal, 2006).

No que se refere à promoção da saúde bucal, revisões da literatura destacam as limitações de intervenções educacionais para produzirem mudanças sustentáveis em longo prazo ou para reduzirem iniquidades em saúde. Uma das maiores críticas tem sido o desenvolvimento de programas isolados de outras iniciativas em saúde, utilizando abordagem estreita e segmentada, separando a boca do corpo. O desafio é a inserção de tópicos de saúde bucal em estratégias mais amplas de promoção da saúde, em que os profissionais trabalhem integrados, utilizando a abordagem dos fatores comuns de risco (Sheiham, Moysés, 2000) e envolvendo membros da comunidade de maneira participativa. As ações educativas devem estar conectadas a uma série de ações complementares em saúde pública, para promover saúde bucal de forma sustentável (Mouradian, Huebner, Ramos-Gomes, 2007; Watt, 2007; Dickson, Abegg, 2000).

Dessa forma, as associações de base comunitária e do setor de voluntariado são apontadas como canais potencialmente importantes para se atuar em promoção da saúde, incluindo saúde bucal 
(Sheiham, 2004). Dickson e Abbeg (2000) sustentam que o envolvimento de potencialidades locais no planejamento e implementação de iniciativas de desenvolvimento comunitário e de melhora da saúde, não é apenas um imperativo ético, mas também um imperativo pragmático. Eymard Vasconcelos (1997) ressalta que, no Brasil, na maioria das regiões, é impossível fazer um trabalho comunitário em saúde sem se relacionar com as várias organizações populares ligadas à Igreja e com seus agentes, e que estes podem ser importantes aliados, sendo preciso conhecer seu trabalho.

A Pastoral da Criança da Igreja Católica é uma dessas organizações que tem se destacado nacional e internacionalmente por atuar na promoção da saúde de gestantes e crianças até seis anos. No ano 2000, a promoção da saúde bucal passou a fazer parte de suas ações básicas. Este estudo objetivou aprofundar o conhecimento sobre o processo de capacitação e materiais de apoio utilizados pelos líderes da Pastoral da Criança, a fim de identificar suas potencialidades e fragilidades para a promoção da saúde bucal.

\section{Método}

O universo de referência da pesquisa foi a Pastoral da Criança na diocese de Curitiba. Esta diocese abrange, além do município de Curitiba, outros nove municípios vizinhos, onde atuam 1.053 líderes comunitários.

Foi utilizada a Metodologia da Avaliação Rápida proposta pelo Centro para o Desenvolvimento e Avaliação de Políticas e Tecnologia em Saúde Pública (CEDETES), Colômbia, para avaliação de efetividade de intervenções em promoção da saúde. Essa metodologia busca desvelar não apenas o cumprimento dos objetivos da intervenção, mas também as mudanças esperadas e não esperadas como consequência da mesma, bem como os fatores que têm contribuído para esses resultados, alcançando uma compreensão dos fenômenos encontrados a partir de uma análise do contexto, processo e resultados (Salazar, 2004). Tem como pressupostos: a redução da brecha entre informação e ação, tendo como usuários primários os tomadores de decisão; a consideração do contexto e cenário político, na análise dos resultados; a participação de todos os interessados no processo avaliativo.

A opção por uma metodologia participativa se apoia na ideia de que a avaliação em Promoção da Saúde deve ser coerente com seus princípios. Tendo como um de seus pilares o empoderamento, a avaliação deve se dar com base em uma lógica emancipatória, participativa e colaborativa. Deve tornar-se um processo de construção de sujeitos, contribuindo para o fortalecimento de indivíduos, grupos e organizações (Brandão, Silva, Palos, 2005).

Para tanto, são previstos os sete passos percorridos nesta pesquisa avaliativa. Primeiramente, realizou-se a caracterização do projeto para avaliação. Nesta etapa, foi construído o marco lógico da intervenção e realizada a análise do contexto. O segundo passo foi o estudo da viabilidade e factibilidade da avaliação, com a definição da equipe avaliadora e seus interesses no processo avaliativo. Fizeram parte desta equipe, 16 atores-chave, que participaram da implementação e que atuam na ação avaliada: formuladores de políticas da Pastoral, representantes dos diversos níveis de gestão, capacitadores e líderes que atuam diretamente com as famílias acompanhadas. Para a realização da sistematização (Salazar, 2004), a equipe avaliadora recuperou e organizou todo o material disponível: projeto original, relatórios, material fotográfico, bem como os materiais didáticos utilizados nas capacitações e atividades dos líderes.

Numa primeira Oficina de Avaliação, empreendeu-se um resgate histórico da ação e discussão do marco teórico, aprofundando conceitos de educação em saúde e promoção da saúde. Segundo Wallerstein, Maltrud e Polacseck (1997), nesta fase é importante compartilhar uma história e criar uma visão comum de futuro, neste caso, o perfil esperado para um líder promotor de saúde bucal. Nessa oficina, realizou-se o terceiro passo da avaliação: definição do alcance da avaliação. Foram refinados a pergunta e objetivo da avaliação. Cumpriu-se ainda, nessa oficina, o quarto passo, com a definição das fontes e métodos de coleta de dados.

O quinto passo foi o trabalho de campo. Procedeu-se à análise documental para se identificar a tendência pedagógica e conteúdos relacionados à saúde bucal nos materiais de apoio utilizados pelas 
lideranças durante as capacitações e atividades. Foram realizadas entrevistas com três informantes-chave na Pastoral da Criança: Coordenação de Saúde Bucal, para aprofundar questões técnicas; Assessoria de Capacitações, para questões pedagógicas; e Coordenação da diocese de Curitiba, para levantar como essas questões se configuravam na prática diária. Realizou-se a observação participante de uma capacitação no Guia do Líder, principal material de apoio utilizado nas capacitações e nas atividades das lideranças. Foram realizados, ainda, dois grupos focais com nove e sete líderes, respectivamente, contemplando-se, dessa forma, o princípio da triangulação (Minayo, Assis, Souza, 2005).

O sexto passo foi o processamento e análise da informação. Os conteúdos das entrevistas e grupos focais foram gravados e transcritos, sendo reunidos com os demais registros para constituição do "corpus" de pesquisa. Como categorias interpretativas foram elencados dois princípios da Promoção da Saúde definidos pela Organização Mundial de Saúde (WHO, 1998): o empoderamento e a integralidade, a partir dos quais foi realizada a análise de conteúdo (Bardin, 1977). Para desvelar como esses princípios se apresentam na formação e atuação dos líderes, foram utilizadas duas categorias de análise:

- tendência pedagógica adotada nos materiais e capacitações, explorando o princípio do empoderamento;

- abordagem dos temas de saúde bucal e sua conexão com outros temas e ações vinculadas aos determinantes ampliados da saúde, para a análise da integralidade.

A equipe avaliadora reuniu-se em uma segunda Oficina de Avaliação para a análise e interpretação dos resultados. Foram levantadas sugestões para superação dos fatores dificultadores e potencialização dos fatores facilitadores da ação avaliada.

O sétimo passo foi a comunicação dos resultados e tomada de decisão. Nesta etapa foram identificados os decisores e seus interesses de informação. Definiram-se os objetivos e estratégias para comunicação dos resultados. Foram realizadas reuniões da coordenadora da equipe avaliadora com alguns dirigentes da Pastoral da Criança em nível nacional e da diocese pesquisada. Discutiramse os principais resultados, conclusões e recomendações da equipe de avaliação. Foi elaborado um resumo executivo, com formato reduzido e linguagem simples, a ser disseminado nos demais níveis hierárquicos da instituição por meio das reuniões mensais de coordenações.

Em cumprimento aos princípios éticos, o projeto foi registrado e aprovado no Comitê de Ética em Pesquisa. Foram obtidos os Termos de Consentimento Livre e Esclarecido pelos diversos sujeitos participantes.

\section{Resultados e discussão}

\section{O conceito de empoderamento e a tendência pedagógica adotada}

A base do trabalho da Pastoral da Criança é a capacitação de líderes comunitários para que possam melhorar seus conhecimentos sobre saúde, nutrição, educação e cidadania, e depois compartilhar o saber com as famílias que acompanham. Ainda que o resultado deste esforço se limitasse a prover informações básicas sobre estes temas para largos segmentos da população, considerando os 1.053 líderes atuantes na diocese, esta proposta já poderia ser relacionada ao processo de potencialização, por integrar o direito de tomar decisões informadas e beneficiar aprendizagens posteriores (Meyer, Mello, Ayres, 2006). Contudo, considerando o anteriormente exposto sobre as concepções pedagógicas e suas consequências em nível individual e coletivo, buscou-se aprofundar o conhecimento sobre os materiais de apoio e as capacitações dos líderes, para uma análise mais apurada de sua adesão ao conceito de empoderamento.

A entrevista com a assessoria de capacitações da Pastoral da Criança revelou o método a ser utilizado nas capacitações, bem como durante as atividades dos líderes:

"Utilizamos uma metodologia baseada na educação popular, trabalhando teoria e prática, uma metodologia que a gente chama de "ver, julgar, agir, avaliar e celebrar" que é usada na Igreja há muitos anos". (entrevista 1) 
Por ser importante detalhar mais o contexto em que esse método se insere, tanto para situá-lo melhor sócio-historicamente, quanto para compreender o que sua adoção pode significar em termos de uma educação libertadora, recupera-se, a seguir, um pouco de seu histórico.

O Concílio Vaticano II - 1962/1965 - consolidou uma nova maneira de se fazer teologia, atenta às realidades do mundo moderno. A II Conferência Episcopal Latino-Americana realizada em Medellín, em 1968, definiu três principais opções: pelos pobres, pelas Comunidades Eclesiais de Base (CEB) e pela libertação integral. No Brasil, este movimento se materializou nos grupos e nas associações operárias de inspiração cristã e nas CEB, que utilizavam, como método de trabalho, o "ver-julgar-agir" em sintonia com os ensinamentos da pedagogia do oprimido de Paulo Freire (2005). Este método esquematizado pelo padre belga Cardijn, para estimular a participação dos leigos na transformação da dura realidade do período entre guerras na Europa, foi posteriormente adotado pelos teólogos da América Latina. O método faz ponte entre educação e vida, por meio de três momentos: (VER) partir da realidade, (JULGAR) formar consciência crítica sobre os problemas, (AGIR) transformar a realidade. A reunião dos bispos da América Latina em Puebla, em 1972, veio confirmar a opção pelos pobres e também pelo método (Boran, 1981).

No contexto sociopolítico e eclesial de 1992, em que ocorreu a Conferência de São Domingos, República Dominicana, os bispos e demais participantes foram formalmente proibidos de trabalhar segundo o método indutivo do "ver, julgar e agir", sendo-lhes imposto um método dedutivo característico da teologia clássica (Boff, Ramos-Regidor, Boff, 1996). Recentemente, durante a preparação da V Conferência Geral do Episcopado Latino-americano, realizada no Brasil em 2007, levantaram-se muitas vozes para pedir explicitamente o retorno ao método (Beozzo, 2007). Diante desta polêmica percebe-se que não se trata de uma mera técnica de trabalho grupal, ao contrário, esse método tem o claro objetivo de desenvolver a consciência crítica e a autonomia dos indivíduos e grupos, o que o aproxima do conceito de empoderamento.

Estas idas e vindas do método "ver, julgar e agir" refletem o que Marcondes (2007) denomina a ambiguidade da questão social na Igreja. Daí a importância da adoção de uma vertente pedagógica, nas pastorais e movimentos sociais, que permita a construção da consciência crítica e a continuidade das mudanças, mesmo em épocas de recuo da Igreja Católica a uma posição teológica mais tradicional, ou em períodos de repressão política, como a ocorrida sob os governos militares.

\section{Análise dos materiais de apoio}

O Guia do Líder é utilizado tanto como roteiro das capacitações iniciais, quanto como material de apoio nas atividades educativas realizadas posteriormente. A tendência pedagógica não está descrita no material, mas algumas características indicam seu direcionamento para a vertente da problematização, utilizando a metodologia do ver-julgar-agir, que na Pastoral da Criança agrega mais duas etapas: avaliar e celebrar. Algumas dessas características são descritas a seguir.

\section{Discussão da realidade antes da teorização e atitude dialógica}

No início de cada ciclo teórico da capacitação, sob o título VER, são propostas algumas questões para discussão antes do início das atividades. Essa discussão leva ao segundo passo do método, que é o JULGAR, que aqui tem o sentido de compreender melhor a realidade a ser transformada. Da mesma forma, o Guia incentiva os líderes a assumirem uma postura dialógica, procurando reconhecer a realidade, os conhecimentos e valores das pessoas como no trecho:

As conversas sobre amamentação podem se basear no que a gestante e seu companheiro querem saber [...] um bom começo é conversar sobre as experiências de amamentação que a gestante conhece [...]. (Pastoral da Criança, 2007, p.34) 


\section{Integração entre teoria e prática}

O Guia está estruturado de forma que, durante a capacitação, alternam-se momentos de concentração teórica e momentos de dispersão, onde os líderes em formação realizam atividades práticas em suas próprias comunidades. Ao final de cada período de concentração, é apresentada uma sugestão de tarefa para a dispersão - momento do AGIR. No início de cada nova etapa teórica, encontra-se uma série de perguntas sob o título - AVALIAR E CELEBRAR -, que estimulam o relato da realidade encontrada nas comunidades, uma avaliação da atividade realizada e a comemoração dos avanços conseguidos.

\section{Adequação da linguagem e ilustrações ao público-alvo}

A linguagem utilizada em todo o material é muito clara e os conceitos técnicos foram convertidos em explicações bastante simplificadas. Observa-se que existiu um cuidado extremo para que os desenhos e fotos refletissem a realidade socioeconômico-cultural das comunidades nas quais este material será utilizado.

A linguagem adotada e a consonância das fotos e desenhos com a realidade da população acompanhada são fatores extremamente positivos do ponto de vista pedagógico. Frei Betto, ao relatar uma experiência vivenciada num programa materno-infantil para mulheres faveladas, afirma:

[...] os médicos falavam em "FM" e as mulheres captavam em "AM" - não conseguiam se sintonizar. Então me chamaram para ver onde estava o "curto-circuito". Percebi que havia uma grande falha no uso do material pedagógico. O material dos médicos era sofisticado [...] As belas mulheres dos áudio visuais, as fotos de bebês tipo propaganda da Johnson etc. Diante daquilo, qual era o raciocínio das mulheres? "Não tem nada a ver comigo, esse é o mundo da patroa". [...] hoje, no meu trabalho de educação popular, cada vez mais isto se confirma: o material pedagógico também não é neutro. (Freire, Frei Betto, 1987, p.59)

\section{O processo de capacitação}

O processo de capacitação inicia-se com a capacitação no Guia do Líder e adquire caráter processual e permanente por meio: das reuniões de coordenação, jornal mensal, programas radiofônicos, capacitações em temas específicos e nas reuniões para reflexão e avaliação. Nestas, os diversos líderes de uma mesma comunidade se reúnem mensalmente para compilar os indicadores colhidos nas visitas, avaliar os resultados, discutindo os problemas encontrados e alternativas de superação. O próprio Guia indica que, nestas reuniões, deve ser utilizado o mesmo método usado nas capacitações: o "ver-julgar-agir-avaliar e celebrar".

Durante a observação participante da capacitação no Guia do Líder, constatou-se que não foram realizadas as etapas do VER, momento de buscar na realidade o tema a ser estudado, antes de iniciar a teorização. Pode-se considerar que o momento do JULGAR, no sentido de ampliar a compreensão dos determinantes maiores dos problemas, foi estimulado durante os momentos de espiritualidade $e$ por conteúdos presentes no Guia. Logo em suas páginas iniciais, onde se aborda a "missão do líder", encontra-se uma análise das condições de vida no país, uma citação do capítulo II da Constituição Dos direitos sociais - e vincula o trabalho dos líderes à luta por acesso a esses direitos, temas que são retomados em outros pontos do material.

O AGIR esteve presente nas atividades práticas realizadas nas comunidades, porém, em menor número do que o previsto no Guia, que alterna permanentemente teoria e prática. Assim, as fases do AVALIAR E CELEBRAR, após cada atividade prática, ficaram reduzidas. Os momentos presenciais de capacitação focaram prioritariamente os conteúdos técnicos presentes no Guia. Desta forma, embora o Guia seja estruturado com tendência participativa, partindo da realidade e alternando teoria e prática, a capacitação observada adotou uma abordagem pedagógica mais tradicional. 
Nas discussões dos grupos focais, o termo "passar informação" foi corriqueiramente utilizado e alguns líderes demonstraram, em suas falas, posturas verticalizadas, características da educação tradicional:

"[...] tem mãe que a gente sofre um pouco pra por na cabeça delas a importância a respeito de tudo". (grupo focal 1)

Por outro lado, alguns líderes revelaram uma tendência dialógica, considerando o contexto da família acompanhada:

“[...] as vezes a gente diz: - Aquela mãe não é interessada [...] mas por quê? Como que ta a vida daquela mãe, como é que ta a auto-estima dela, de repente ela ta com dificuldade do marido desempregado [...] ta com alguma dificuldade grande que vai daí a gente saber. Não, vamos lá. Saber trabalhar, saber conversar, saber chegar até ela". (grupo focal 1)

Estes resultados podem estar refletindo o pouco enfoque dado ao método "ver, julgar e agir" nas capacitações, já que, como afirma Freire (2005, p.22-3):

[...] se na experiência de minha formação, que deve ser permanente, começo por aceitar que o formador é o sujeito em relação a quem me considero objeto [...] terei a possibilidade, amanhã, de me tornar o falso sujeito da "formação" do futuro objeto de meu ato formador.

Ao ser adotada uma concepção tradicional nas capacitações, a maior probabilidade é de que os líderes a reproduzam em seu dia-a-dia, mesmo porque esta é a concepção dominante na educação formal, que vivenciaram desde sua infância. Trapé e Soares (2007), estudando as concepções de educação em saúde dos Agentes Comunitários de Saúde (ACS), profissionais cujas funções assemelham-se às dos líderes, também encontraram, predominantemente, posturas transmissivas, e, em menor frequência, concepções dialógicas pautadas no respeito aos conhecimentos da população. As autoras atribuíram esse resultado à ênfase no caráter técnico das capacitações, e a uma compreensão política limitada do processo educativo.

Quando questionada sobre quem são os capacitadores na Pastoral da Criança, a assessora de capacitações afirmou que:

“[...] são pessoas que se destacam no acompanhamento das famílias, que têm facilidade de se comunicar, que sabem manejar grupos, são pessoas que sabem ler e escrever e que conseguem, de alguma forma, reproduzir o que eles tiveram nas capacitações deles pra outras pessoas". (entrevista 1)

Sobre a existência de capacitação pedagógica para os líderes ou para os capacitadores, declarou não existir uma formação específica:

“[...] durante a capacitação do Guia do Líder existem vários momentos em que é falado o como agir, o como trabalhar com a família, mas não existe uma capacitação só pra isso, diferenciada [...] o que nós sempre orientamos nas capacitações é que eles ouçam bastante, troquem experiências e também algumas atitudes que eles devem evitar como criticar, julgar, penalizar estas famílias por não estarem entendendo suas orientações ou não seguirem o que eles falaram". (entrevista 1)

Assim sendo, percebeu-se que existe a preocupação desta instituição com o tipo de postura educativa adotada pelo líder em seu trabalho, e, ao mesmo tempo, a Pastoral da Criança já assumiu seu caminho pedagógico ao produzir o Guia do Líder utilizando o método "ver-julgar-agir". Buscando o "nó critico" que vem dificultando a aplicação desta metodologia, a equipe avaliadora apontou 
a falta de formação pedagógica para os capacitadores. Avaliou-se que eles têm de compreendê-la profundamente, seus objetivos e os porquês de utilizá-la nas capacitações, tornando-se capazes de estimular esta postura pedagógica nas diversas atividades dos líderes.

Abordando a capacitação dos ACS, Nascimento e Correa (2008) relatam que, visando qualificar a atuação destes profissionais, foi realizada, além da capacitação técnica, a formação pedagógica de seus capacitadores. Objetivou-se que os mesmos se apropriassem da metodologia da problematização. Esta foi adotada por potencializar a aprendizagem do aluno que, como agente de transformação social, deve ser capaz de detectar problemas reais e buscar para eles soluções originais. Ou seja, se o objetivo é formar educadores críticos e criativos, os capacitadores devem não apenas utilizar o método nas capacitações, mas reforçar a importância dessa dinâmica de trabalho durante as atividades do líder.

Uma das coordenadoras entrevistadas apontou um tipo de atividade que os líderes são estimulados a realizar nas comunidades:

"A Pastoral orienta a fazer roda de conversa. Não são duas ou três pessoas não. É reunir a comunidade, fazer uma roda com uma pessoa orientando, coordenando, pra ver aquilo que é necessário". (entrevista 3)

Nos jornais mensais e na publicação "Dicas", dirigida aos coordenadores, foram encontradas várias citações sobre esta atividade, porém, nos grupos focais e oficinas, não foram feitas referências a essa estratégia, sugerindo que sua importância precisa ser reforçada com as lideranças. Processos educativos que tenham como meta o empoderamento das comunidades demandam abordagens que valorizem a criação de espaços de participação, para identificação e análise crítica de seus problemas (Carvalho, 2004).

Outro ponto levantado como dificultador da utilização do método foi a limitação de tempo nas capacitações. Os líderes afirmaram:

“[...] porque a gente faz a capacitação, mas é muito tema no livro [...] muita coisa, vai corridinho". (grupo focal 1)

Os participantes da equipe avaliadora apontaram dificuldades de abordar todos os assuntos e realizar todas as atividades previstas:

“Em capacitações mais antigas eram formados grupos, feitas dramatizações sobre visita domiciliar [...] agora é tudo passado muito rápido [...] na pressa de capacitar muita gente, sendo poucos capacitadores, se perdem algumas coisas". (oficina de avaliação 2)

A utilização do método tradicional calcado na "transmissão" de conteúdos, sem dúvida, se mostra mais rápida. Logicamente, a abertura de canais de diálogo para problematização dos conteúdos e busca de soluções demanda mais tempo. Daí a importância da discussão, com os capacitadores, do perfil de líder que se pretende formar. Enquanto a primeira abordagem se liga a um perfil mais técnico, voltado para repasse de informação, a segunda se mostra fundamental para formação de agentes de transformação social (Nascimento, Correa, 2008; Pereira, 2003).

Ainda em relação ao empoderamento, dois outros depoimentos mostraram-se importantes. $\mathrm{O}$ primeiro refere-se à percepção dos líderes sobre o impacto das ações:

“Tem umas (famílias) que acham que a gente só por ser líder não é nada, elas acreditam mais na agente comunitária do que na líder". (grupo focal 1)

Quando foi discutido sobre a busca de parcerias para a realização das atividades, a percepção se repetiu: 
“Pra gente ir atrás como uma simples líder procurar este apoio [...] então teria que ser de cima, porque a gente não vai ter força". (grupo focal 2)

Os termos 'só por ser líder' e 'uma simples líder' denotam a percepção de impotência por parte destes entrevistados e revelam, de certo modo, um paradoxo diante do conceito de liderança.

Durante a segunda oficina de avaliação, analisando as causas desta percepção, o grupo concluiu que a autoestima dos líderes está baixa, e que deveria ser feito um trabalho que levasse ao reconhecimento do valor pessoal. A fala de uma coordenadora é bastante esclarecedora:

“O valor pessoal precisa ser resgatado, que se chama cidadania [...] você descobrir que é um cidadão. Esta fala - eu sou só uma líder - é de uma pessoa que não se identificou, não se descobriu. Então nós, capacitadores, temos que trabalhar a auto-estima, o valor pessoal e levar que ela consiga identificar-se [...] eu faço parte de uma nação, um país, com direitos, acesso". (oficina de avaliação 2)

Este depoimento vem ao encontro do que Paulo Freire denomina assumir-se:

Uma das tarefas mais importantes da prática educativo-crítica é propiciar as condições em que os educandos [...] ensaiam a experiência profunda de assumir-se. Assumir-se como ser social e histórico, como ser pensante, comunicante, transformador, criador, realizador de sonhos [...]. (Freire, 2004, p.41)

A própria OMS (WHO, 1984) reconhece que garantir o acesso à informação, ampliando o conhecimento em saúde, sem aumentar a capacidade de controle e perspectivas de mudança, apenas contribui para gerar ansiedade e fomentar a sensação de impotência. Ou seja, apenas o conhecimento técnico não é suficiente para o empoderamento. Mais uma vez, a resposta a este problema pode estar na estratégia utilizada na formação e atuação dos líderes. Uma das líderes presentes na segunda oficina declarou:

"Eu acho que isto vem acontecendo mais por falta do nosso "ver-julgar e agir" e a falta de mais avaliações e reflexões em nossas reuniões". (oficina de avaliação 2)

Esta líder constatou, empiricamente, que a otimização na utilização deste método é o caminho necessário e suficiente para a superação desta sensação de impotência. Boufleuer (1991) aponta o método dialógico como forma de devolver a autoconfiança aos educandos. Só por meio da reflexão e ação sobre uma realidade a ser recriada, pode se dar o processo de tornar-se sujeito.

\section{Integralidade das ações}

Outro ponto fundamental diz respeito à forma como a saúde bucal é abordada nos materiais e capacitações. A análise dos materiais de apoio mostrou que os conteúdos específicos de saúde bucal não formam uma sessão à parte, mas foram sendo introduzidos em cada fase da gestação e do desenvolvimento da criança. Como anteriormente comentado, as ilustrações e orientações são adequadas ao contexto socioeconômico, contemplando diferenças regionais. Desta forma, considerase que esses materiais conseguem recolocar a boca dentro do corpo e esse dentro do contexto social das pessoas (Moysés, Kusma, 2008).

Alguns temas são recorrentes nos materiais e depoimentos na Pastoral da Criança: aleitamento materno, alimentação saudável, higiene corporal, prevenção de acidentes e violência doméstica. Estes são fatores comuns de risco para diversos problemas, como: desnutrição. obesidade, cárie e trauma dentário. Assim sendo, constata-se que o trabalho realizado utilizando a abordagem de fatores de risco/fatores de saúde comuns a diversos problemas acaba por favorecer a conexão entre saúde bucal e geral, promovendo a integralidade (Watt, 2007; Sheiham, Moysés, 2000). 
Durante os grupos focais foram levantados os outros temas trabalhados nas capacitações que podem promover saúde bucal. O tema alimentação foi o mais relacionado pelos líderes:

“Tem tudo a ver. Tem que ter uma alimentação saudável, comer bastante verduras, frutas [...] A alimentação é a base, seria importante fazer esse reforço". (grupo focal 2)

Foram correlacionados, ainda, problemas bucais e gerais:

“[...] não adianta só tratar a desnutrição se não tem a higiene na boca também. A desnutrição pode ser dos próprios dentes, por causa dos dentes estragados". (grupo focal 2)

Contudo, percebeu-se certa limitação na capacidade dos líderes em fazer estas conexões, indicando a necessidade de se aprofundarem estas relações durante as capacitações iniciais e na capacitação específica de saúde bucal que será estruturada.

Finalmente, é importante ressaltar a existência de ações complementares, que dão suporte às ações básicas, como a alfabetização de jovens e adultos, voltada às próprias líderes e às famílias acompanhadas. Os programas de geração de renda são adaptados às características regionais e, na diocese pesquisada, acontece o projeto de qualificação das líderes e mães em serviços domésticos. Outra ação complementar é a formação para o controle social. O objetivo do desenvolvimento desta estratégia é a capacitação de um articulador no Conselho de Saúde, em cada município onde a Pastoral da Criança atua. O articulador é responsável pelo preenchimento e envio mensal da Folha de Acompanhamento do Conselho de Saúde.

Percebeu-se a preocupação desta organização com a integralidade das ações e a criação de um ambiente domiciliar e comunitário que dê suporte às ações educativas. Sabe-se, porém, que este princípio da promoção da saúde está intimamente ligado a outro, como afirma Buss (2000), as políticas saudáveis têm, na intersetorialidade, sua ferramenta operacional. Todas as Cartas da Promoção da Saúde (Brasil, 2002) foram unânimes em indicar a construção de alianças para o enfrentamento de desafios tão amplos. A complexidade da realidade encontrada foi citada nos grupos focais como fator dificultador do desenvolvimento das ações, sendo estampada na fala de uma líder:

\footnotetext{
“Eu faço visita de manhã às vezes. E daí você vê o marido dela lá. - Há, hoje to sem ânimo, meu marido já correu fazer entrevista, correu atrás de emprego não conseguiu [...] uma casa de quatro paredes, duas peças, sete pessoas dentro da casa. O marido não consegue emprego, pela condição dele [...] já vem da baixa escolaridade [...] Então às vezes essa mãe tem isso de ter preguiça [...] porque a vida dela não é um mar de rosas. Não tem escova, não tem pasta, não tem uma alimentação saudável, não tem um sabão pra lavar a roupa, não é verdade? A realidade é dura". (grupo focal 2 )
}

A declaração de uma coordenadora alia-se a esta constatação, atestando ainda a insuficiência das ações educativas para a concretização do lema da organização - "para que todas as crianças tenham vida e vida em abundância":

“[...] a gente percebe que esta questão do líder chegar [...] eu tenho para ensinar, vocês vão aprender, isso não funciona. O soro caseiro é uma coisa que funcionou bastante, porque é uma técnica simples de se fazer e que surtiu efeito contra a desidratação [...] hoje existem outros problemas que não é uma "tecnicazinha" [...] falar em anemia, não envolve só a colherzinha do soro e fazer com a água [...] tem que trabalhar a questão do ferro, como é que está o acesso da criança ao serviço de saúde, que alimentação a mãe está dando pra criança? Então, são outros fatores que envolvem a questão educativa e uma mudança de comportamento, que não é só o líder chegar lá com uma orientação que ele vai conseguir mudar'". (entrevista 1) 
Estas considerações vêm ao encontro dos questionamentos de Meyer e colaboradores quanto à necessidade dos processos educativos incorporarem as questões de vulnerabilidade:

O componente social da vulnerabilidade envolve o acesso às informações, as possibilidades de metabolizá-las e o poder de incorporá-las a mudanças práticas na vida cotidiana, condições estas diretamente associadas ao acesso a recursos materiais, a instituições sociais como escola e serviços de saúde, ao poder de influenciar decisões políticas [...] dentre outras, que precisam então ser incorporadas às análises de vulnerabilidade e aos projetos educativos às quais elas dão sustentação. (Meyer, Mello, Ayres, 2006, p.1340)

Assim sendo, buscou-se conhecer mais profundamente como os mecanismos de capacitação dos líderes têm fomentado o estabelecimento de parcerias para promoção de saúde. Ao trabalhar a questão do planejamento das atividades, o Guia do Líder (Pastoral da Criança, 2007, p.137) coloca as seguintes questões: "Que recursos temos nas nossas comunidades? Que pessoas podem nos ajudar em nossa missão?". Quando orienta a organização das Reuniões para Reflexão e Avaliação (p.247), traz outros questionamentos: "Que outras ações para essa ou outras famílias devem ser iniciadas? Quem pode ajudar?" E afirma que, para solucionar problemas que afetam várias famílias, pode ser necessário reunir entidades da comunidade.

Nos grupos focais, os líderes manifestaram a necessidade de se buscarem parceiros para realização das ações, porém observou-se que as parcerias indicadas dirigiam-se majoritariamente à realização das atividades educativas:

“Do próprio posto de saúde se a gente conseguisse fazer com que uma vez ou outra eles mesmos fossem lá e falassem [...] ou poderia ser até da universidade [...] pra vir alguém de fora fazer alguma coisa, porque a verdade é que a gente não consegue fazer tudo". (grupo focal 2)

As coordenações divergiram quanto ao papel das lideranças na busca de parceiros, bem como sobre a abordagem deste tema nas capacitações. Uma das coordenações afirmou:

“[...] o líder quando é capacitado ele é orientado a nunca trabalhar sozinho, sempre procurar parcerias [...] com a unidade de saúde, com o conselho tutelar quando necessário [...] e isto é passado em capacitação. Inclusive se orienta que se trabalhe com as associações de moradores porque dali surgem melhorias pra própria comunidade. Aconselhamos que os nossos líderes participem de seus conselhos locais, distritais e municipais... porque a comunidade sozinha não resolve...ela tem que se unir a outras entidades, a outros órgãos, pra poder melhorar suas condições". (entrevista 3)

Outra coordenação reiterou a necessidade do trabalho em redes:

“[...] se não tiver a comunidade ajudando em outros sentidos, a associação de moradores, a prefeitura, o serviço de saúde, se não estiverem envolvidos os outros setores da comunidade [...] a gente vai ter menos resultados do que a gente espera". (entrevista 1)

Afirmou, contudo, que esta responsabilidade extrapola a função dos líderes e que este assunto não é focado na capacitação deles:

“[...] como ele é um voluntário e vai ter determinado tempo do mês pra fazer este trabalho, ele tem as outras instâncias da Pastoral que vão ter que estar atuando neste sentido [...] os coordenadores têm uma capacitação específica que foi montada justamente pra ele ter esta visão do todo. O líder não tem este papel, não por incapacidade, mas ele já tem as suas atividades [...] então os coordenadores é que tem esse papel de movimentar a comunidade. $\mathrm{E}$ 
aí quando ele percebe nas reuniões de reflexão e avaliação quais são os problemas, ele tem que chamar as outras instâncias da comunidade pra trabalhar junto". (entrevista 1)

Na segunda oficina, quando estes resultados foram analisados, o grupo apontou que a construção de redes deve ser um trabalho descentralizado. Enfatizou-se que todo trabalho na Pastoral é conjunto, cada nível tem de buscar as parcerias correspondentes ao seu nível de atuação. As lideranças e coordenações de comunidade buscam parceiros nas comunidades em que atuam, fazem contato com a unidade de saúde, grupos de jovens e outros recursos locais. Já as demais coordenações devem fazer contatos maiores, como com secretarias de saúde e prefeituras.

\section{Conclusões}

Concluiu-se que a tendência pedagógica adotada pela instituição pesquisada está em sintonia com o princípio do empoderamento. Porém, existe a necessidade de se aprofundarem as questões pedagógicas, especialmente durante a formação dos capacitadores dos líderes, para que a abordagem educativa assumida possa ser evidenciada de modo mais efetivo na prática. Considera-se que a inserção da saúde bucal na Pastoral da Criança conseguiu superar uma falha grave e constante em outras propostas educativas, ao integrar este tema aos demais conteúdos e ações já existentes. A constatação de que os problemas sociais tornaram-se muito mais complexos em relação ao início do trabalho da Pastoral da Criança há 26 anos, leva à conclusão de que a formação e atuação focadas na informação de conteúdos técnicos não têm mais o impacto esperado. Hoje, a capacitação tem de ultrapassar a dimensão técnica e alcançar uma dimensão política, formando lideranças capazes de acessar políticas públicas e buscar parcerias para construção de redes que deem suporte e sustentabilidade às suas ações.

Considera-se que a metodologia avaliativa utilizada oportunizou um processo pedagógico participativo que favoreceu o empoderamento e desenvolvimento de capacidades de reflexão e ação da equipe avaliadora. Um movimento em que pessoas avaliam as próprias ações e tentam transformar o seu cotidiano de maneira mais confiante nas habilidades e capacidades desenvolvidas ao longo do processo coletivo.

\section{Colaboradores}

As autoras Silvia Queiroz e Simone Moysés participaram da elaboração do artigo, de sua discussão, redação e revisão do texto. Os autores Samuel Moysés, Beatriz França e Julio Bisinelli participaram da revisão bibliográfica, de discussões e revisão do manuscrito.

\section{Referências}

BARDIN, L. Análise de conteúdo. Lisboa: Edições 70, 1977.

BEOZZO, J.O. A V Conferência Geral do Episcopado Latino-americano em Aparecida: contextos sociopolítico e eclesial. Rev. Teol. Cienc. Religião, v.6, n.6, p.1-10, 2007. Disponível em: <http://www.unicap.br/revistas/teologia/arquivo/artigo\% 201.pdf>. Acesso em: 10 mar. 2008.

BOFF, L.; RAMOS-REGIDOR, J.; BOFF, C. A teologia da libertação: balanços e perspectivas. São Paulo: Ática, 1996.

BORAN, J. O senso crítico e o método ver-julgar-agir: para pequenos grupos de base. São Paulo: Loyola, 1981.

BORDENAVE, J.E.D. Alguns fatores pedagógicos. In: BRASIL. Ministério da Saúde (Org.). Capacitação pedagógica para instrutor supervisor da área da saúde. Brasília: Ministério da Saúde, 1989. p.19-26. 
BOUFLEUER, J. P. Pedagogia latino-americana: Freire e Dussel. Ijuí: Unijuí, 1991.

BRANDÃO, D.B.; SILVA, R.R.; PALOS, C.M.C. Da construção de capacidade avaliatória em iniciativas sociais: algumas reflexões. Ensaio: Aval. Pol. Publ. Educ., v.13, n.48, p.361-73, 2005.

BRASIL. Ministério da Saúde. As cartas da promoção da saúde. Brasília: Ministério da Saúde, 2002.

BUSS, P.M. Promoção da saúde e qualidade de vida. Cienc. Saude Colet., v.5, n.1, p.16377, 2000.

CARVALHO, S.R. Os múltiplos sentidos da categoria "empowerment" no projeto de Promoção à Saúde. Cad. Saude Publica, v.20, n.4, p.1088-95, 2004.

DICKSON, M.; ABEGG, C. Desafios e oportunidades para a promoção da saúde bucal. In: BUISCHI , Y.P. (Org.). Promoção de saúde bucal na clínica odontológica. São Paulo: Artes Médicas, EAP/APCD, 2000. p.39-72.

FREIRE, P. Pedagogia do oprimido. 47.ed. São Paulo: Paz e Terra, 2005.

Pedagogia da autonomia: saberes necessários à prática educativa. 29.ed. São Paulo: Paz e Terra, 2004.

FREIRE, P.; BETTO, Frei [Carlos Alberto Libânio Christo]. Essa escola chamada vida. 5.ed. São Paulo: Ática, 1987.

GOHN, M.G. Empoderamento e participação da comunidade em políticas sociais. Saude Soc., v.13, n.2, p.20-9, 2004.

MARCONDES, W.B. Participação popular na saúde pelos caminhos da prática educativa. 2007. Tese (Doutorado) - Escola Nacional de Saúde Pública, Fundação Oswaldo Cruz, Rio de Janeiro. 2007.

MEYER, D.E.E.; MELLO, D.F.; AYRES, J.R.C.M. "Você aprende. A gente ensina?" Interrogando relações entre educação e saúde desde a perspectiva da vulnerabilidade. Cad. Saude Publica, v.22, n.6, p.1335-42, 2006.

MINAYO, M.C.S.; ASSIS, S.G.; SOUZA, E.R.D. Avaliação por triangulação de métodos: abordagem de programas sociais. Rio de Janeiro: Fiocruz, 2005.

MOURADIAN, W.E.; HUEBNER, C.E.; RAMOS-GOMES, F. Links beyond access: the role of family and community in children's oral health. J. Dent. Educ., v.71, n.5, p.619-31, 2007.

MOYSÉS, S.T.; KUSMA, S. Promoção de saúde e intersetorialidade na abordagem familiar. In: MOYSÉS, S.T.; KRIGER, L.; MOYSÉS, J. (Orgs.). Saúde bucal das famílias: trabalhando com evidências. São Paulo: Artes Médicas, 2008. p.247-57.

NASCIMENTO, E.P.L.; CORREA, C.R.S. O agente comunitário de saúde: formação, inserção e práticas. Cad. Saude Publica, v.24, n.6, p.1304-13, 2008.

PASTORAL DA CRIANÇA. Guia do líder da pastoral da criança. Curitiba: Pallotti, 2007.

PEREIRA, A.L.F. As tendências pedagógicas e a prática educativa nas ciências da saúde. Cad. Saude Publica, v.19, n.5, p.1527-34, 2003.

QUEIROZ, S.M.P.L. Efetividade do processo de capacitação dos líderes da Pastoral da Criança para promoção da saúde bucal em Curitiba, Brasil. 2008. Dissertação (Mestrado) - Pontifícia Universidade Federal do Paraná, Curitiba. 2008.

SALAZAR, L. Evaluación de efetividad en promoción de la salud: guía de evaluación rápida. Santiago de Calli: CEDETES/CDC/OPS, 2004.

SHEIHAM, A. Abordagens de saúde pública para promover saúde periodontal. In: BÖNECKER, M.; SHEIHAM, A. (Orgs.). Promovendo saúde bucal na infância e adolescência: conhecimentos e práticas. São Paulo: Santos, 2004. p.27-43. 
SHEIHAM, A.; MOYSÉS, S.J. O papel dos profissionais de saúde bucal na promoção da saúde. In: BUICHI, Y.P. (Org.). Promoção de saúde bucal na clínica odontológica. São Paulo: Artes Médicas/APCD, 2000. p.23-37.

TRAPÉ, C.A.; SOARES, C.B. A prática educativa dos agentes comunitários de saúde à luz da categoria práxis. Rev. Latino-am. Enferm., v.15, n.1, p.142-9, 2007.

VASCONCELOS, E.M. Educação popular nos serviços de saúde. São Paulo: Hucitec, 1997.

WALLERSTEIN, N.; MALTRUD K.; POLACSECK, M. Participatory evaluation workbook for community initiatives. New Mexico: Department of Health, Public Health Division, Healthier Communities Unit, 1997.

WATT, R.G. From victim blaming to upstream action: tackling the social determinants of oral health inequalities. Commun. Dent. Oral Epidemiol., v.35, n.1, p.1-11, 2007.

WESTPHAL, M.F. Promoção da saúde e prevenção de doenças. In: CAMPOS, G.W.D.S. et al. (Orgs.). Tratado de saúde coletiva. São Paulo: Hucitec, 2006. p.635-67.

WORLD HEALTH ORGANIZATION - WHO. What is evidence on effectiveness of empowerment to improve health? Copenhagen: WHO, Regional Office for Europe, Health Evidence Network, 2006.

1998.

Promotion evaluation: recommendations to policymakers. Copenhagen: WHO,

Ottawa charter for health promotion: first international conference. Copenhagen: WHO, 1986.

. Discussion document on the concept and principles. In: (Org.). Health promotion: concepts and principles, a selection of papers presented at working group on concepts and principles. Copenhagen: WHO, 1984. p.20-3.

QUEIROZ, S.M.P.L. et al. Itinerarios para promoción de la salud bucal: la capacitación de líderes en la Pastoral del Niño de la Iglesia Católica en Brasil. Interface - Comunic., Saude, Educ., v.14, n.34, p.619-32, jul./set. 2010.

El propósito de esta investigación evaluativa ha sido el de analizar la capacitación de los líderes de la Pastoral del Niño de la Iglesia Católica e identificar el potencial y la fragilidad para promoción de la salud bucal. Se ha utilizado la Metodología de Evaluación Rápida, de caracter participativo. Se han realizado talleres de evaluación, análisis documentales, entrevistas con informaciones clave, grupos focales y observación participante de una capacitación en la Guía del Líder. Teniendo como categorías interpretativas el apoderamiento y la integralidad, se ha procedido al análisis de contenido. La salud bucal se trabaja de forma integrada a los demás temas y acciones complementarias dan soporte a las acciones educativas. La tendencia pedagógica adoptada por la institución investigada contempla el principio de apoderamiento. No obstante cuestiones técnicas han tenido mayor énfasis en la capacitación que en las pedagógicas. Las discusiones sobre cuestiones pedagógicas y trabajo en redes, en las capacitaciones, se consideran puntos fundamentales para consolidación y ampliación de la acción evaluada.

Palabras clave: Promoción de la salud. Educación en salud. Apoderamiento. Integralidad. Redes sociales. 